\title{
Women Blogs and Aestheticised Consumption
}

\section{Billge Gürsoy}

\section{Doi:10.5901/mjss.2013.v4n10p249}

\begin{abstract}
Ideology is a system of ideas that aspires both to explain the world and to change it. Aesthetic founded as a philosophical discipline by A. G. Baumgarten is the science of what is sensed and imagined. The ideology of aesthetics is used to shape subjects and give them a new form. Individuals accept imposed politics or consumption objects, without force when they are aestheticised. For example the fascists aestheticised politics, the global capitalist system aestheticised consumption and created consumption societies. Especially through media, consumption products appeal to senses and are easily accepted. Perceiving consumption as aesthetic; people incline towards consumption and express themselves by the products they consume. This study examines and compares two women blogs: "Shopping Consultant" in Turkish and "A Mom in Red High Heels' in English. In these blogs, it can be observed that consumers find consumption aesthetic; they are satisfied to have consumer identity. Aestheticised consumption which is created by the "ideology of aesthetic", seems global and suitable to global capitalist system's needs.
\end{abstract}

Keywords: Aesthetic, Consumption, Women blogs

\section{Introduction}

Today aesthetic plays an important role in the society. As a result of aesthetic of consumption, individuals have become voluntarily part of consumption society by consuming and obtaining pleasure from consumption. As the aesthetic is related with senses and includes pleasure and imagination, an aestheticized individual inclines towards the aesthetic things. Ideology is a system of ideas that aspires both to explain the world and to change it. For this reason global capitalist system can aestheticize objects and situations, suitable to their benefit and provide individuals' acceptance. The Ideology of Aesthetics, (Eagleton, 2000) underlines that aesthetic gives new form to subjects and it has "law like" role. Because aesthetic, "sister of logic" is the science of what is sensed and imagined and as our beliefs are based on feelings, sensation, when we obey to aesthetics we feel ourselves free without force. For this reason, for the continuation and the stability of the order, aesthetic has an important role. Today, aesthetic plays its' role of creating and keeping consumer identity through the media. Consumer identity is visible worldwide because as Eagleton says, "consumption object causes the collapse of the different identities" (2010: 467). Not only consumption objects but also some other things can also be aestheticised, to smooth the tension between rationality and sensibility. For example during the 1920s and 30s, the fascists have -as Benjamin says, "aestheticised politics" (Oskay, 2007: 65)

By the development of global capitalism, social order and consumption are aestheticized and consumption societies are created. In order to understand these societies, Frankfurt School philosophers studied capitalism and created terms such as "cultural industry", "one dimensional man." The culture industry involves the production of works for reproduction and mass consumption. Under capitalism all production is for market, goods are produced not only to meet human needs and desires but for the sake of profit. (Adorno, 2001: 5) Today's media is both mirror and leader of consumption craziness and consumer identity which can be seen as "one dimensional". For example, "Shopping Consultant" blog is rewarded among women blogs category in 2011 in Turkish. "A Mom in Red High Heels" blog, has similar subject and chosen as one of the best 50 blogs in 2011, in English. When they are compared, it can be observed that consumers unite in the frame of the aesthetic of consumption, their tendency and taste are alike in global scale, legitimizing Eagleton's "ideology of aesthetic".

\section{From ideology to the ideology of aesthetic}

\subsection{Ideology}

Ideology is a form of social or political philosophy in which practical elements are as prominent as theoretical ones. It is a system of ideas that aspires both to explain the world and to change it. The word first appeared in French as idéologie at 
the time of the French Revolution. Ideology today is generally taken to mean not a science of ideas, but the ideas themselves. In his book Ideology An Introduction (2007: 1, 2) Eagleton gives some definitions of ideology as follows: (a) the process of production of meanings, signs and values in social life; (b) a body of ideas characteristic of a particular social group or class; (c) ideas which help to legitimate a dominant political power; (d) false ideas which help to legitimate a dominant political power; (e) systematically distorted communication; (f) that which offers a position for a subject; (g) forms of thought motivated by social interests; (h) identity thinking (i) socially necessary illusion; (j) the conjecture of discourse and power; ( $k$ ) the medium in which conscious social actors make sense of their world; (I) action oriented set of beliefs; $(m)$ the confusion of linguistic and phenomenal reality; $(n)$ semiotic closure; (o) the indispensable medium in which individuals live out their relations to a social structure; $(p)$ the process whereby social life is converted to a natural reality.

According to Eagleton, all these formulations are not compatible with one another. For example if ideology means any set of beliefs motivated by social interest, it cannot simply signify the dominant forms of thought in a society (Eagleton, 2007: 2) To argue for a 'political' rather than 'epistemological' definition of ideology does not claim that politics and ideology are identical. Politics has its own sort of signification, which need not be necessarily ideological. According to Eagleton, "very often, it refers to the ways in which signs, meanings and values help to reproduce the dominant social power; but it can also denote any significant conjuncture between discourse and political interests" (2007: 221)

"The sociological view that ideology provides the 'cement' of social formation, or the 'cognitive map' which orientates its agents to action, is too often depoliticising in effect, voiding the concept of ideology of conflict and contradiction" (Eagleton, 2007: 222). According to Eagleton, ideology in its dominant forms is often seen as a mythical or imaginary resolution of such contradictions, but it is not wise to overestimate its success in achieving this goal" (2007: 222).

\subsection{Aesthetic, Sister of Logic}

Philosophers since antiquity have been interested in our experiences and judgments about beauty and ugliness. They have tried to understand the nature of these experiences and judgments, and they have also wanted to know whether these experiences and judgments were legitimate. The philosophical discipline of aesthetic did not receive its name until 1735, when the twenty-one year old Alexander Gottlieb Baumgarten introduced it in his master's thesis to mean epistêmê aisthetikê, or the science of what is sensed and imagined. The word "aesthetic" comes from Greek word aesthesis or aisthanesthai. It refers to the whole region of human perception and sensation. According to Baumgarten, aesthetic is a kind of logic, "sister of logic" and it is gnoseologia inferior. On the other hand, logic is gnoseologia superior. Both logic and aesthetic want to find the truth, but the truth in the aesthetic area is called beautiful (Tunalı, 2007: 13-15). According to Eagleton, it is born as a woman subordinate to man but with her own humble, necessary task to perform. (2000: 16)

Ideology is not set of abstract doctrines for Eagleton, but it makes us uniquely what we are, constitutive of our identities. On the other hand, it presents itself as 'everyone knows that', a kind of anonymous universal truth. Althusser thinks ideology is a question of 'lived relations' but according to Eagleton, there are no such relations which do not involve beliefs and assumptions. Most general of all meanings of ideology stresses the social determination of thought, it lights up general field of culture from a particular angle ( Eagleton, 2007: 1-31).

According to Rosencrantz, ugly is also an aesthetic category. L. Wittgenstein (1889-1951) thinks aesthetics should not only be limited by beautiful. G. T. Fechner (1801-1887) thinks psychologically. He says, pleasure phenomena in aesthetics should also be examined and he uses the name "hedonic" for this science (Tunall, 2007: 15,16). According to Umberto Eco, in ancient Greece "beauty" has not an independent situation. Eco thinks, we can say that until Pericles period, there was not a theory of real aesthetics. Beauty was related with some other qualities, for example Delphi oracle said "the most beautiful is the most fair" (Eco, 2006: 37). According to Eco "graceful", "pleasant", "delightful", "wonderful", and similar words used with the word "beautiful" are adjectives showing our liking. There is a tight connection between good and beautiful (8). In addition mostly it is said that the aesthetic object gives pleasure and it helps to smooth the tension between sensuality and rationality.

\subsection{The Ideology of Aesthetic}

The construction of the modern notion of the aesthetic artefact is inseparable from the construction of the dominant ideological forms of the modern class society. Aesthetics is born as a discourse of the body. Aesthetics is not a challenge to political authority, but it seems to be ideological and it is in absolutist power. This power needs to give importance to 
"sensible life" for its own purpose. Baumgarten's aesthetic cognition mediates between the generalities of reason and the particulars of sense. (Eagleton, 2000: 1-13) The vision of the aesthetic/moral project, according to Eagleton, is to create

\begin{abstract}
"...universal order of free, equal, autonomous human subjects, obeying no laws but those they give to themselves. This bourgeois public sphere breaks decisively with the privilege and particularism of the ancien régime, installing the middle class in image, if not in reality, as a universal subject... What is at stake here is nothing less than the production of an entirely new human subject - one which, like the work of art itself, discovers the law in the depths of its own free identity." (2000: 19)
\end{abstract}

The binding forces of bourgeois social order are habits, pieties, sentiments and affections. The power in such order is "aestheticised". The law dissolves to custom. In addition Kant's "duty" becomes attractive. His "lawfulness without a law" is paralel to authority which is not authority. The aesthetic unites us with all the authority of a law ...And according to Eagleton, this is certainly one major reason why the aesthetic has figured so centrally in bourgeois thought. (2000: 75)

By the mid-eighteenth century, London had become the largest centre of international trade. The middle class has won certain historic victories within political society. Legal, economic, political transformations translated into new forms of social practice. Theory of beauty, aesthetic helped this transformation. For example according to Eagleton, structures of power became structures of feeling. Burke writes about manners:

Manners are more important than laws. Upon them in a great measure, the laws depend. The law touches us but here and there, and now and then. Manners are what vex and soothe, corrupt or purify, exalt or debase, barbarise or refine us... They give their whole form and colour to our lives. According to their quality they add morals, they supply them, or they totally destroy them (Eagleton, 2010: 69)

Manners shape the human subject from inside. Franco Moretti writes:

It is not enough that social order is legal; it must also appear symbolically legitimate...It is also necessary that a free individual, not as a fearful subject, but as a convinced citizen, one perceives the social norms as one's own. One must internalise them and fuse external compulsion with internal impulse into a new unit until the former is no longer distinguishable from the latter. This fusion is what we call 'consent' or 'legitimating'. If Bildungsroman appears to us still today as essential, pivotal point of history, this is because it has succeeded in representing this fusion with a force of conviction and optimistic clarity that will never be equalled again (Eagleton, 2000: 44)

The growing aestheticisation of social life, then represents a major hegemonic advance on the part of the governing block. According to Eagleton, there is a difficult tension within the bourgeois society, between the ideology of production and between the ideologies of production. Viewed from the standpoint of consumption the world is uniquely ours. Capitalism centres the subject in the sphere of values, only to decentre it in the realm of things (2000: 44, 92). Our beliefs are based on feelings, sensation and at the root of social relations there is aesthetics. The capitalist system produced aesthetics of consumption. It keeps us together, appeals to our senses and seems more important than laws.

\title{
3. Critical Theory and "one dimensional man"
}

\subsection{Critical Theory}

Critical theory, a broad-based Marxist-oriented approach to the study of society, was first developed in the 1920s by the philosophers Max Horkheimer, Theodor Adorno, and Herbert Marcuse at the Institute for Social Research in Frankfurt, Germany. They and other members of the Frankfurt School, as this group came to be called, fled Germany after the Nazis came to power in 1933. The institute was relocated to Columbia University in the United States and remained there until 1949, when it was re-established in Frankfurt. By the time Western capitalism had entered a new stage, dominated by growing monopolies and increasing governmental intervention in the economy (Jay, 1996: 43). According to Jay, American mass culture became one of the central concerns of the Frankfurt School (172).

Critical theorists asked why the working classes in advanced capitalist countries were generally unmotivated to press for radical social change in their own interests. They attempted to develop a theory of capitalist social relations and to analyze the various forms of cultural and ideological oppression arising from them. In Dialectic of Enlightenment (1947), Horkheimer and Adorno argued that the celebration of reason by thinkers of the 18th-century Enlightenment had led to the development of technologically sophisticated but oppressive and inhumane modes of governance, exemplified 
in the 20th century by fascism and totalitarianism. Horkheimer wrote to Lowenthal, "...consumption tends to vanish today, or should I say, eating, drinking, looking, loving, sleeping become consumption, for consumption already means that man has become a machine outside as well as inside of the workshop?" (Jay,1996: 214).

In works published in the 1950s and 60s, Marcuse attacked both the ideological conformism of managerial capitalism and the bureaucratic oppression of the communist "peoples' democracies." Critical theorists initially believed that they could liberate people from false beliefs, or "false consciousness," and in particular from ideologies that served to maintain the political and economic status quo, by pointing out to them that they had acquired these beliefs in irrational ways (e. g., through indoctrination). In the end, however, some theorists, notably Marcuse, wondered whether the forces tending to promote ideological conformity in modern capitalist societies had so compromised the perceptions and reasoning powers of most individuals that no rational critique would ever be effective. According to Martin Jay, Marcuse seemed to be arguing for an identity theory, which contrasted to Frankfurt School's general stress on non-identity. "In fact in Marcuse's writings the aversion to identity was far fainter than in Horkheimer's or Adorno's" (Jay, 1996: 60-61).

\subsection{One Dimensional Man}

"The identity principle strives to suppress all contradiction, and for Adorno this process has been brought to perfection in the reified, bureaucratised, administered world of advanced capitalism..." (Eagleton, 2007: 127) Marcuse projected this vision in One-Dimensional Man: Studies in the Ideology of Advanced Industrial Society (1964). He argued that the modern capitalist society has the artificial satisfactions of consumer culture. Marcuse criticised dominant philosophical and intellectual currents: positivism, analytic philosophy, technological rationality and conformist thinking. According to Kellner, Marcuse was one of the first critical theorists to analyze the consumer society through analyzing how consumerism, advertising, mass culture and ideology integrate individuals into and stabilize the capitalist system (Marcuse, 1991: xxx). His book One-Dimensional Man contains a theory of advanced industrial society that describes how changes in production, consumption, culture and thought have produced conformity. Consumer capitalism integrates individuals into its world of thought and behaviour (1991: xi). About individuals integrating into technological society, Marcuse writes,

As beneficial products became available to more individuals in more social classes, it becomes a way of life-a good way of life. It militates against qualitative change. Thus emerges a pattern of one-dimensional thought and behaviour in which ideas, aspirations, objectives are either repelled or reduced to terms of this universe (12).

Marcuse's analysis is based on technological world which controls its subjects. According to Marcuse "pretechnological, two dimensional cultures are different from one dimensional societies" (63), but pre-technological images began to loose their power (65). Marcuse thinks, in technological society, "the people recognize themselves in their commodities; they find their soul in their automobile, hi-fi set, split-level home, kitchen equipment, the very mechanism which ties the individual to his society has changed..." (9). He underlines that in capitalist consumer societies, humans become extensions of the commodities that they buy. In the one dimensional society, the subject is assimilated into the object and follows the dictate of external objective norms and structures. The subject looses the ability to discover more liberating possibilities. One dimensional man has lost or losing individuality, freedom, the ability to control his own destiny (xi).

\section{4. women blogs and Aestheticised Consumption}

"Blog" is online journal where an individual, group, or corporation presents a record of activities, thoughts or beliefs. Some blogs operate as news filters, collecting various online sources and adding short comments and internet links. Other blogs concentrate on presenting original material. Tim Berners-Lee, created the first "blog" in 1992 to outline and render visible the ongoing development of the Web and the software necessary to navigate this new space. In December 1997, J. Barger, an early online presence, coined the term web log to describe his Web site "RobotWisdom.com". While the history of the term is new, the same cannot be said of the identity of the first blogger. Depending on the definition of a blog, Berners-Lee may not qualify as the first blogger. Claimants to this title include Justin Hall, a college student who started an online list at links. net in 1994; Carolyn Burke, who began publishing Carolyn's Diary online in 1995; and Dave Winer, who has published Scripting News online since April 1, 1997. By October 2005 there were 19. 6 million blogs, a number that has been doubling roughly every five months. Approximately 70,000 new blogs are created each day. Despite the phrase "every person a blogger", blogs are not likely to replace the mainstream media. Instead, blogs will 
continue to complement existing news media by allowing anyone to set up a Web site dedicated to his or her particular interest or perspective.

"Shopping Consultant" blog is rewarded in women blogs category in 2011 in Turkey. Tammy Gibson's "A Mom in Red High Heels" blog, has similar subject and is chosen as one of the best 50 blogs in 2011 . When they are compared, it can be observed that consumers unite in the frame of the aesthetics of consumption, their tendency and taste are alike in global scale, legitimizing "ideology of aesthetics". Shopping Consultant" blog is in Turkish, it has about 1300 members, is sponsored by Schwarzkof and received the third reward in the competition sponsored by Turkcell (2011). The blog includes magazine news, photographs of famous people, comments on clothing, sharing information and advices about clothes, accessories, beauty, and diets. A Mom in Red High Heels" blog has about 200 million users, its content is similar to the mentioned Turkish blog but it is much more richer than "Shopping Consultant" in material, for example it includes many links of shops, brands, touristy places, books, videos and courses about beauty, make up etc.

\subsection{Subjects and Language of the Blogs}

Shopping Consultant (original name: Alışveriş Danışmanı) whose most of the members are housewives, includes topics such as Brands, names of places for shopping, pregnancy, children, vacation with children, health, beauty, diets, magazine news, astrology, second hand selling, doctor addresses, illnesses (i.e. Psychiatry, pedagogy, depression, panic attack...). Some dialogues among women can be called as feminist because a great deal of them is about criticising men and traditional role of men and women. The language of the blog is personal, speech like and has a unique jargon. Although the blog is prepared in Turkish, many English words and sentences such as "out of service", "you might also like" can be seen. Turkish includes lots of exclamation marks, capital letters and sound words to indicate strong emotions. For example, "DAN DAN DAN!!" "Hişşşt!" In this blog, most of grammar usage is wrong, verbs and words are shortened. Examples of commonly used words are shop, blog, price, sale, nice... Most used sentences are "I like", "I bought", "I want", and "you must have", "holiday shopping", "follow me with fashion", "who is more beautiful?", "you might also like"... The blog presents a few advertisements and links to other addresses such as "facebook".

The topics in A Mom in Red High Heels whose members seem to be married and unmarried women, include brands, names andplaces for shopping, pregnancy, children, vacation by children, health, beauty, diet, magazine news, elevating income, joining Twitter and Fun Club, introducing books (about beauty, nails, teeth etc.), confidence building, inner beauty (i.e. ecologic behaviour), video courses for "to meet your most beautiful self". The last one is online training platform with expert demos and support, saying "all dedicated to helping you discover your true beauty". The language is informal, speech like and comments section includes lots of exclamation marks to indicate strong emotions. Capitalization is used to create the effect of emphasis (i.e. who loves a fabulous makeover? I DO! Is your hand raised too?). Commonly used words are shop, clearance, beauty, style, new look, must-haves. Used Sentences such as "Shopping is my therapy", "AWESOME summer dresses for your wardrobe!", "So you finally have the hair colour you LOVE!", Get the Goods, "Must-Have: Structured Satchel", "Must-Have Chic and Sophisticated Jacket" are seen in the blog. The blog presents more advertisements than "Shooping Consultant" blog and give links to "twitter", "shops" and "courses"...

In both blogs traditional gender roles can be seen. Women are responsible from children, house-cleaning, family diet, cooking and they have to look well everywhere including work places and it seems that they have to learn how to be more beautiful, aesthetic by consuming aestheticized consumption objects.

\subsection{Aesthetics and Cinderella}

As mentioned before, aesthetics is the science of what is sensed and imagined. Both blogs include colourful photographs, attractive colours which appeal to our senses and many of them seem beautiful. In addition most of the subjects and language are about aesthetics. (i.e. to like, to feel good, to be beautiful). Most importantly not only the products but the consumption itself, "shopping" seems aesthetic. The aesthetics of consumption is visible in these blogs, the users have common consumption discourse in both bogs and consumption products have leading roles. Perceiving consumption as aesthetic has a great role in women's tending to consumption and expressing themselves by the products they consume. In addition there is place for imaginary. Women having traditional gender roles, have opportunity to change themselves like Cinderella by buying a dress and shoes. The following paragraphs taken from "A Mom in Red High Heels" are a good example for this modern Cinderella. 
Once upon a time, there was a mom who worked ... a lot. She blogged, she homeschooled, she did laundry, dishes, sweeping and all the other not-so-fun chores that it takes to run a household. She was tired of the day to day and dreamed of the day her prince would whisk her away for one magical evening.

Then one day, she purchased a dress... an AH-mazing dress. It had ruffles. It was sophisticated and girlie all at the same time. It made her feel wonderful. From the moment she tried it on; she knew this dress was special. It made her feel... Magical, Gorgeous, Special, Confident, plus, when she wore it, her husband looked at her with a twinkle in his eye.

But, something was missing. Shoes. Beautiful, fantastic, princess-worthy shoes.... One SUPER lucky girl will win a pair of original Cinderella Slippers re-imagined by the amazing shoe designer, Christian Louboutin! To add to the excitement, the winner is invited to a private event at Disneyland! DREAMS DO COME TRUE ...just like Cinderella!

As it is seen from the last paragraph, the winner of the shoes will be invited to Disneyland. According to Baudrillard "The Disneyland imaginary is neither true nor false; it is a deterrence machine set up in order to rejuvenate in reverse the fiction of the real" (Baudrillard, 1983: 25,26). Baudrillard names Disneyland as "orders of simulation, plays of illusions and phantasms" (23). All these terms are in the area of aesthetics, the science of what is sensed and imagined. The paragraphs above given from the "A Mom in Red High Heels" are good examples for advertisement, aestheticised consumption objects such as dresses, shoes, places and gender roles. Furthermore it is an important fact that, women want to own these objects with their free will because they appeal to their senses.

\section{Conclusion}

Beauty seems to have important role in many lives. It is no surprise that philosophers since antiquity have been interested in our experiences about beauty. Today the science of beauty, aesthetic helps to create and keep global consumer identity, and this identity is visible in women blogs. These blogs can be explained by the terms culture industry or Marcuse's one dimensional society, but "the ideology of aesthetics" fits best to explain the content of these blogs, because they address to the senses and imagination. Most expressed concepts are about beauty, liking, charm, fancy... As owners of the blogs and users find consumption aesthetic and as they believe that they will feel and look beautiful by fashionable products, they seem satisfied to be part of the consumption system.

It seems the aesthetics of consumption has global property in the tension of local and global. Both blogs justify Eagleton's "the ideology of aesthetics". As aesthetics managed to keep bourgeois together in the eighteenth century, by aestheticised moral and manners, it still manages to design consumer society by creating aestheticised consumer identity. Our beliefs are based on feelings, sensation and it can be seen that at the root of social relations in "A Mom in Red High Heels" and "Shopping Consultant /Alışveriş Danışmanı" blogs there is aesthetics, they are examples of aesthetic consumption that satisfies its' users. Aesthetics presents itself as a kind of anonymous universal truth and it can be said that it is the truth of "aesthetic Cinderella."

\section{References}

Adorno, T. W. (2001). The Culture Industry, (Ed.) Bernstein, J. M. London: Routledge.

Baudrillard, J. (1983). Simulations. USA: Semiotext (e), Inc.

Eagleton, T. (2000). The Ideology of the Aesthetic. USA: Blackwell Publish.

Eagleton, T. (2007). Ideology An Introduction. London: Verso.

Eagleton, T. (2010). The Ideology of the Aesthetic. (In Turkish). Istanbul: Doruk Publish. Gözkan, B., Hünler, H., Amaner, T., Ates, N., Dost, A., Kiliç, E., et al. (Translated by).

Eco, U. (2006). History of Beauty. Akkoyunlu, A. C. (Translated by). Istanbul: Dogan Publish. (Original published in 2005).

Encyclopaedia Britannica, http://www.britannica.com.

Internet Encylopedia of Philosophy, "Kant's Aesthetics", http://www.iep.utm.edu

Jay, M. (1996). The Dialectial Imagination-A History of the Frankfurt School and the Institute of Social Research, 1923-1950. Berkeley, Los Angeles, London: University of California Press.

Lye, J. (1997). "Ideology", retrieved from http://www.brocku.ca/english/jlye/ideology.php

Marcuse, H. (1991). One Dimensional Man. USA: Beacon Press.

Oskay, Ü. (2007). Aestheticised Life-Walter Benjamin. (in Turkish). Istanbul: Derin Publish.

Tunalı, I. (2007). Aesthetic. (In Turkish). Istanbul: Remzi Kitabevi.

Stanford Encyclopaedia of Philosophy, http://plato.stanford.edu 